\title{
Dictynna
}

Dictynna

Revue de poétique latine

$1 \mid 2004$

Varia

\section{Nyctegresiae Romanae. Exégèse homérique et retractatio de la Dolonie chez Virgile et Ovide}

Jean-Christophe Jolivet

\section{(2) OpenEdition}

1 Journals

\section{Édition électronique}

URL : http://journals.openedition.org/dictynna/163

DOI : 10.4000/dictynna.163

ISSN : $1765-3142$

Édition imprimée

ISBN : 2-84467-088-1

\section{Référence électronique}

Jean-Christophe Jolivet, « Nyctegresiae Romanae. Exégèse homérique et retractatio de la Dolonie chez Virgile et Ovide », Dictynna [En ligne], 1 | 2004, mis en ligne le 15 novembre 2010, consulté le 10 septembre 2020. URL : http://journals.openedition.org/dictynna/163 ; DOI : https://doi.org/10.4000/ dictynna.163

Ce document a été généré automatiquement le 10 septembre 2020.

\section{(i) (9)}

Les contenus des la revue Dictynna sont mis à disposition selon les termes de la Licence Creative Commons Attribution - Pas d'Utilisation Commerciale - Pas de Modification 4.0 International. 


\title{
Nyctegresiae Romanae. Exégèse homérique et retractatio de la Dolonie chez Virgile et Ovide
}

\author{
Jean-Christophe Jolivet
}

1 Lorsqu'Enée contemple les représentations de la guerre de Troie sur les murs du temple de Junon, lors de son arrivée à Carthage, il voit la Dolonie, l'exploit de Diomède ramenant au camp achéen les chevaux de Rhésos ${ }^{1}$; à côté de cette représentation, le jeune Troïle, tué par Achille, est emporté sur son char $^{2}$; sa lance ${ }^{3}$ retournée, trace un sillon dans la poussière (uersa puluis inscribitur hasta) : le malheur de Troie, dont le nom même de Troïlos est emblématique ${ }^{4}$, se trouve ainsi inscrit dans la poussière ${ }^{5}$. Mais, à quelque temps de là, un des protagonistes raconte la Dolonie à Calypso: il s'agit d'Ulysse qui dessine sur le sable, avec une baguette, sa version de la terrible nuit iliadique du chant 10 : ille leui uirga / in spisso litore pingit opus ${ }^{6}$. Si le sillon tracé par la lance de Troïle dans la poussière est par nature éphémère, l'opus dessiné avec art par Ulysse (pingit opus) s'inscrit plus distinctement, plus profondément, dans le sable humide du rivage (spisso litore). L'homme d'Ithaque y trace l'itinéraire qu'il dit avoir emprunté pour ramener les chevaux de Rhésos chez les Achéens. L'une et l'autre représentations, ainsi, se répondent. Mais la réécriture métaphorique d'Ulysse est-elle vouée à une postérité plus longue? Non, car les flots capricieux viennent effacer l'œuvre d'une baguette légère et élégiaque (leui uirga) ${ }^{7}$, alors que, paradoxalement, le sillon de la lance de Troïlos, fruit d'un hasard funeste, demeure inscrit dans le marbre de Carthage. Et pourtant, les deux textes qui sont le support de ces représentations nous sont parvenus...

2 La Dolonie a fortement influencé la poésie latine. Sans parler de la Nyctegresia d'Accius, il est fait allusion à plusieurs reprises à cet épisode dans l'Enéide ; outre sa figuration sur les murs du temple de Junon, outre les questions posées par Didon à Enée durant le banquet carthaginois ${ }^{8}$, Virgile s'est largement inspiré de la Dolonie iliadique et de son exégèse alexandrine ${ }^{9}$ pour la sortie nocturne de Nisus et Euryale dans le chant $9^{10}$. Quant à Ovide, il évoque cinq fois l'épisode homérique, dans l'Ibis (627 sq.), qui souligne 
la parenté des exploits de Nisus et Euryale et de la Dolonie, dans l'Art d'aimer, les Amours $(1,9,17-27)^{11}$, la première Héroïde et le chant 13 des Métamorphoses. La latinité d'argent enfin a imité l'épisode, Stace dans le chant 10 de la Thébaïde et Silius Italicus dans le chant 7 des Punica.

Or le chant 10 de l'Iliade a soulevé bien des questions exégétiques dès l'antiquité. Les commentateurs lui attribuaient une place à part, notamment du fait qu'il formait un tout autonome ${ }^{12}$ et qu'un certain nombre de soupçons pesaient sur son caractère authentiquement iliadique : il aurait été, selon les scolies, intégré à l'Iliade à l'initiative de Pisistrate ${ }^{13}$.

Il s'agit en effet d'une aristie atypique : après l'échec de l'ambassade auprès d'Achille, Ulysse et Diomède partent de nuit vers le camp troyen dans le but de s'enquérir des intentions d'Hector pour le lendemain (Iliade, 10, 204 sq.) ; mais durant cette expédition nocturne, il n'y a pas de combat singulier dans les règles de l'art, en plein jour, à la loyale, devant les autres guerriers. Ulysse et Diomède massacrent un prisonnier sans armes, Dolon, avant d'égorger par traitrise Rhésos et les siens, trahis par leur sommeil. Oubliant leur mission de renseignement, ils reviennent au camp achéen avec le butin qu'ils ont pris et surtout les chevaux de Rhésos. La critique moderne s'est attardée sur les problèmes d'éthique héroïque posés par la Dolonie. L'un des arguments avancés pour distinguer le chant 10 du reste de l'Iliade le chant 10 est le caractère peu héroïque de l'action de Diomède et Ulysse durant cette nuit ${ }^{14}$. On souligne à l'envi le rôle d'Ulysse et de ses ruses déloyales. Il y a là un problèmes de prépon ${ }^{15}$. Cette question n'était certainement as étrangère à Virgile dont la Nyctegresia, comme l'a montré SchmitNeuerburg, met l'accent sur les questions éthiques.

5 L'un des problèmes majeurs du chant, que je me contenterai d'évoquer rapidement, a donc trait aux problèmes d'éthique héroïque. La lecture de la Dolonie homérique à travers sa réplique virgilienne, la Nyctegresia de Nisus et Euryale, ne résout pas entièrement la question car, si les héros virgiliens font l'objet d'une célébration, ils meurent victimes de l'appât du gain ${ }^{16}$. Ces deux expéditions constituent-t-elles de véritables exploits, des aristies, apportant le kléos aux héros ? Cela n'allait peut-être pas de soi dans l'antiquité. Ainsi, Antisthène, dans l'Ajax et l'Ulysse qui reprennent la controverse de l'Armorum Judicium ${ }^{17}$, revient sur un certain nombre de questions relatives au comportement d'Ulysse durant la guerre de Troie. Dans son discours justificatif, contre Ajax, défenseur des vieilles vertus guerrières et partisan inconditionnel du combat à la loyale, au grand jour, le héros d'Ithaque souligne en particulier l'efficacité des coups de main nocturnes auxquels il a procédé: ov̉ үò $\rho$

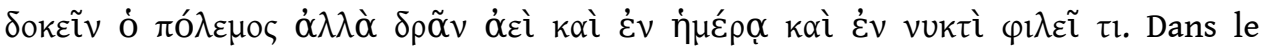
domaine latin cette fois, la question du caractère héroïque du coup de main d'Ulysse et Diomède se pose peut-être depuis longtemps. Il est possible qu'Accius ait déjà intégré dans sa Nyctegresia ce questionnement éthique sur la valeur héroïque de la sortie nocturne de Diomède et d'Ulysse. Le fragment huit de la pièce manifeste en effet une différence d'appréciation de cette action entre deux personnages ${ }^{18}$ :

Illos suapte induxit uirtus : tu laudem illorum leuas ${ }^{19}$.

6 Ce débat apparemment canonique se trouve repris dans le chant 13 des Métamorphoses: si Ulysse vante la Dolonie, Ajax qualifie les actions de Diomède et de son compagnon de uilia merita (101). Quant à l'Enéide, Turnus, reprenant la substance de la controverse entre Ulysse et Ajax chez Antisthène, y qualifie les coups de main nocturnes de la guerre de Troie d'inertia facta et fait l'éloge du combat au grand jour ( 9,150 et 153). 
7 Mais, outre les questions d'éthique hérö̈que, le chant 10 posait aux lecteurs anciens un certain nombre de difficultés parce qu'il mentionnait des usages guerriers atypiques, par exemple, en ce qui concerne l'armement des héros, ou encore, question soulevée dès Aristarque, l'équitation ${ }^{20}$. Le chant 10 est le seul où l'on voie un héros où des héros ? à cheval ${ }^{21}$. La question des chevaux semble avoir retenu l'attention de Virgile et d'Ovide. Partons du problème homérique du chant 10 : on sait que l'exploit essentiel de cette nuit de massacre est la prise, par Diomède et Ulysse, des chevaux de Rhésos, qui, selon certaines traditions, constituait une condition de la prise de Troie. Cet exploit est tellement illustre qu'il se trouve même représenté sur les murs du temple de Junon à Carthage, au chant 1 de l'Enéide ${ }^{22}$. De même, Didon, parmi les faits marquants de la guerre, interroge Enée précisément sur ces chevaux thraces (1,751-752). Ainsi la prise des chevaux est-elle un élément essentiel de la Dolonie : quand Diomède et Ulysse rentrent au camp des Achéens, Nestor «dompteur de chevaux » ne les questionne pas sur la réalisation de leur mission de renseignement, mais il les interroge sur la prise de ces chevaux extraordinaires $(10,543-545)$ :

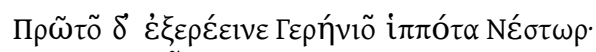

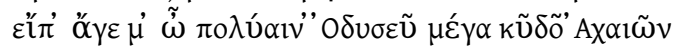

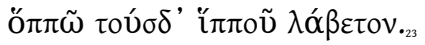

De fait, la mission de renseignement n'a pas été remplie, les deux héros reviennent sans être parvenus à se renseigner clairement sur les intentions d'Hector pour les actions $\mathrm{du}$

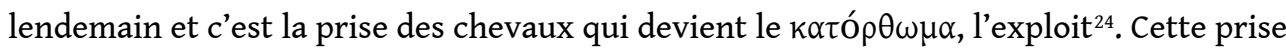
de chevaux et ce problème d'équitation anachronique dans le cadre de l'Iliade sont traités de façon fort différente chez Ovide et chez Virgile, mais dans les deux cas, la question semble occuper une place centrale.

\section{Ovide : la glorieuse chevauchée d'un Ulysse equum domitor}

9 Le récit de la chevauchée nocturne des héros achéens recelait pour les alexandrins un certain nombre d'ambiguïtés ; on l'a dit, l'équitation n'est pas un usage iliadique et les commentateurs mettent ce manquement aux mœurs homériques sur le compte de l'urgence. C'est d'abord la question de savoir si Ulysse montait ou non à cheval qui semble avoir défrayé la chronique alexandrine. Les textes homériques et les scolies dressent d'Ulysse la figure d'un homme qui, en sa qualité d'insulaire, n'est guère familier des chevaux ${ }^{25}$. C'est aussi pour cette raison que, dans le chant 10 de l'Iliade, les chevaux de Rhésos reviendraient à Diomède, alors qu'Ulysse doit se contenter, modestement, des dépouilles de Dolon ${ }^{26}$. Ces considérations se greffaient en outre sur une ambiguïté du texte homérique. A deux reprises au cours du chant 10, les verbes relatifs à l'équitation semblent s'appliquer au seul Diomède : pour certains interprètes, il était clair qu'Ulysse n'était pas monté à cheval durant cette nuit fameuse ${ }^{27}$. Ainsi, après le massacre perpétré dans le camp de Rhésos, Ulysse prépare - avec, il est vrai, un grand savoir faire -, les chevaux et l'on voit Diomède monter à cheval (513-514) ${ }_{23}$. Plus loin encore, Diomède s'arrête pour récupérer les dépouilles de Dolon, il saute à terre, tend les dépouilles à Ulysse et remonte à cheval (528-529) :

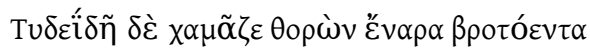

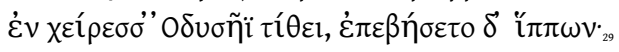


Pourtant, lorsque les deux hommes arrivent aux nefs, ils sautent, tous deux cette fois,

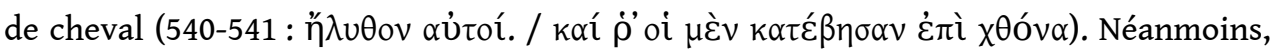
l'emploi des verbes au singulier dans les deux premiers passages semblait accréditer l'idée que seul Diomède montait à cheval, comme en témoignent certaines scolies ${ }^{30}$ :

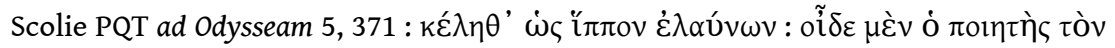

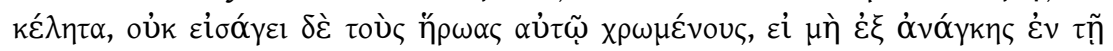

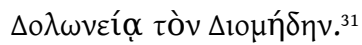

11 En outre, un passage d'Eustathe mentionne explicitement l'existence du problème (820,

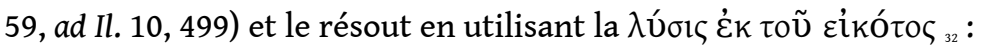

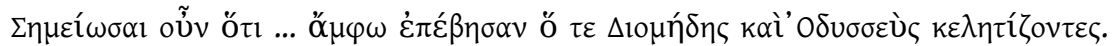

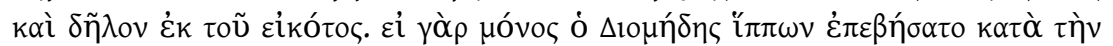

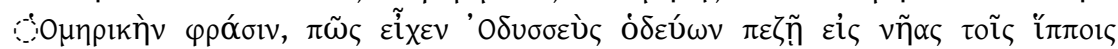

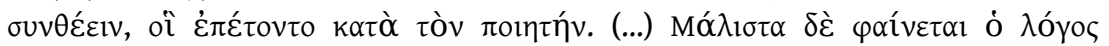

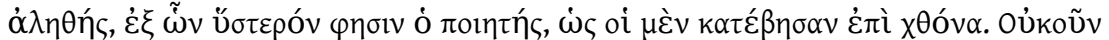

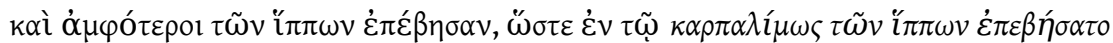

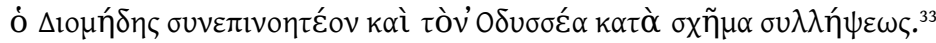

Un problème connexe concernait l'appropriation des chevaux par Diomède ${ }^{34}$, qui ne laissait à Ulysse que les maigres dépouilles de Dolon. Les scoliastes justifiaient cette

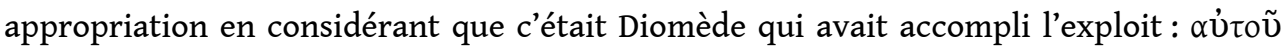

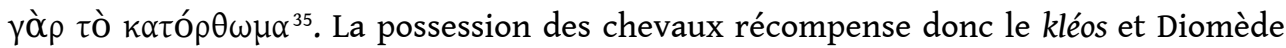
manifesterait par la conservation des chevaux sa supériorité sur Ulysse $^{36}$. Les commentateurs soulignent par ailleurs la modestie d'Ulysse qui, dans son récit à Nestor, s'abstient de revendiquer pour lui la capture des chevaux :

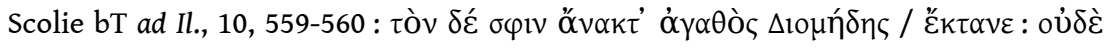

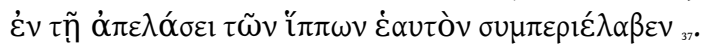

Comme on pouvait s'y attendre, le fictor fandi Ulixes n'a plus la même modestie chez Ovide ; il aime briller auprès des dames et revendique avec une certaine insistance pour lui et pour lui seul la capture des chevaux de Rhésos. Non seulement l'Ulysse ovidien monte à cheval, mais c'est lui qui a ramené les chevaux (voire le char) de Rhésos : dans l'Ars, Ulysse raconte la guerre de Troie à Calypso. La situation narrative évoquée par l' Ars (2,123-142) démarque, on le sait, la situation narrative mise en place dans l'Enéide; de même que Didon interroge Enée sur les chevaux de Rhésos, de même, Calypso demande à Ulysse de lui raconter la Dolonie (pulchra Calypso / exigit Odrysii fata cruenta ducis) ; Ulysse raconte plusieurs fois (iterum) la prise des chevaux, qu'il s'attribue, sans vergogne; il montre précisément l'itinéraire qu'il a emprunté à cheval et dessine sommairement le tout sur le sable, à l'aide d'une baguette :

«Illic Sithonii fuerant tentoria Rhesi :

Hac ego sum captis nocte reuectus equis. »

Dans les Métamorphoses, Ulysse revient sur l'épisode lorsqu'il raconte ses exploits devant l'assemblée achéenne. Comble du raffinement, son récit comporte la solution au problème aristarchéen de l'équitation dans la Dolonie (cf. supra Scol. PQT ad Odysseam 5, 371) : il n'a pas monté les chevaux de Rhésos; ceux-ci étaient attelés à un char, et ce char était vraisemblablement le char de Rhésos (13, 249-252) :

Petii tentoria Rhesi inque suis ipsum castris comitesque peremi atque ita captiuo, uictor uotisque potitus, ingredior curru laetos imitante triumphos. 

currus dans les Métamorphoses; le pluriel equi - de même que tigri ou leones -, peut désigner par métonymie l'attelage pour le char $^{38}$. Cet usage rejoint précisément une ambiguïté du texte homérique relevée par Eustathe : pourquoi est-il dit au vers 529 que

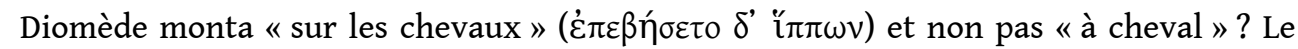
pluriel grec est habituellement employé pour désigner l'attelage d'un char ${ }^{39}$. En réalité, on a pu noter que tout se passait comme si les deux héros s'emparaient du char de Rhésos, mais dans la suite aucune mention n'est faite du véhicule, il aurait fallu pour le moins atteler de nouveau les chevaux au char, dont Ulysse les avait détachés dans un premier temps ${ }^{40} \ldots$ Le Rhésos du pseudo-Euripide semble, lui aussi, jouer sur cette ambiguïtét1, avant qu'Ovide ne consacre la "version » du char qui résout, en quelque

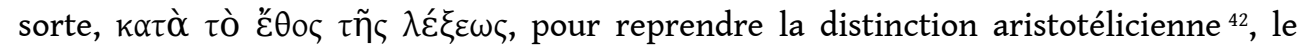
problème homérique de l'usage de l'équitation dans la Dolonie ${ }^{43}$; si la mention des chevaux désigne un char par métonymie, il n'y a plus d'équitation dans le chant 10 de l' Iliade. A vrai dire, on peut toujours imaginer qu'Ovide se contente de reprendre une version présentée, par exemple, par Accius, mais la précision d'autres allusions philologiques aux commentaires de la Dolonie permet également de présenter l'hypothèse d'une dépendance directe des commentateurs alexandrins. Il est à rappeler que le vol du char était l'une des options envisagées par Diomède, qui préféra pourtant, à titre d'exploit, massacrer les Thraces (Iliade, 10, 503-506).

La gloire de l'exploit, qui devient une espèce de retour sur un char triomphal, est fortement marquée par l'attention que les destinataires intradiégétiques portent aux récits latins de la Dolonie ; Didon s'intéresse aux chevaux ramenés par Diomède et, dans la première Héroïde, la prise des chevaux de Rhésos fait l'objet d'une mention particulière. Pénélope, qui écrit à Ulysse, a entendu raconter la Dolonie (45-46) :

Vsque metu micuere sinus, dum uictor amicum

Dictus es Ismariis isse per agmen equis.

Le prestige de ces chevaux tenait à leur rapidité légendaire et à leur brillance extraordinaire. Toutefois, ils n'avaient peut-être pas très bonne réputation. On remarquera à ce propos une précision donnée par Servius : commentant les vers 751-752 du chant 1 de l'Enéide, il indique la raison pour laquelle Didon est si intéressée par les chevaux capturés par Diomède : pour Servius, il s'agit sans conteste de ceux de Rhésos et ces chevaux thraces seraient les descendants de ceux du roi Diomède : Thracis equos humano sanguine pingues (Métamorphoses, 9, 194), ceux-là mêmes qu'Hercule devait conquériri ${ }^{44}$.

Servius ad Aen., 1, 752 : Quales Diomedes equi : (...) de his interrogat quos sustulit Rheso. " quales » autem dixit ac si diceret, anne sic feroces ut illi a quibus ducebant originem. Diomedes enim, rex Thracum, habuit equos qui humanis carnibus uescebantur. Hos Hercules occiso crudeli tyranno abduxisse perhibetur : de quibus dicuntur supra memorati equi originem ducere ${ }^{45}$.

Une expression proverbiale, transmise par Aulu-Gelle : «Ille homo habet equum seianum ", apporte un autre éclairage sur ces aimables cavales. Le cheval de Séius, descendant des chevaux de Rhésos ne portait apparemment pas bonheur ${ }^{46}$. Quoi qu'il en soit, si la généalogie proposée par Servius n'est pas une variante tardive, la conquête des chevaux de Rhésos reproduit le paradigme du labor herculéen; cette dimension herculéenne, est d'ailleurs bien attestée par le De Incredibilibus d'Héraclite $(31,1)^{47}$ : 
dans la notice consacrée aux chevaux de Diomède, l'exploit d'Hercule consiste précisément en ce qu'il a pu les atteler :

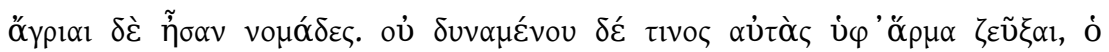

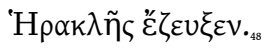

Cet exemple justifie à la fois l'importance qui lui est accordée dans l'Enéide et le fait que l'Ulysse ovidien veuille à tout prix revendiquer le mérite de ce vol (de même qu'il a voulu s'approprier exclusivement la gloire du rapt du Palladium). Il est difficile d'imaginer que la version adoxographique mise en place par Ovide soit indépendante des problèmes philologiques alexandrins ou remonte, par exemple, au traitement de l'épisode chez Accius. Ce que l'on a pu considérer autrefois comme une variante mythographique repose au contraire sur les exégèses du poème homérique.

\section{Fictor fandi Ulixes}

Le fait qu'Ulysse, contre la lettre du texte homérique et contre les exégèses alexandrines, revendique la capture des chevaux et du char de Rhésos vient en fait confirmer les soupçons qui, très tôt, pèsent sur Ulysse narrateur, dans l'Iliade, de la Dolonie. Les scoliastes notaient déjà une certaine tendance du héros d'Ithaque à pervertir la réalité dans ses récits et à s'associer aux mérites de Diomède. C'est le seul Diomède qui, dans l'Iliade, tue Dolon ${ }^{49}$. Mais dans le récit d'Ulysse à Nestor, l'homme d'Ithaque revendique indument une part de cet acte, ce qui entraîne le commentaire suivant :

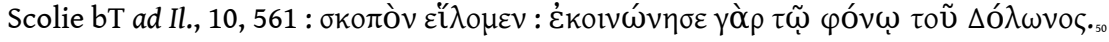

21 Cette manière de s'associer aux exploits de Diomède est commentée par Ulysse qui se glorifie sans vergogne de son compagnonnage d'armes avec le fils de Tydée (Métamorphoses, 13, 239-242) :

At sua Tydides mecum communicat acta.

Ulysse a bien lu les scholies: il emploie un verbe, communicare, qui est un hapax dans toute la langue épique latine ${ }^{51}$. Ce communicat est tout simplement l'exacte

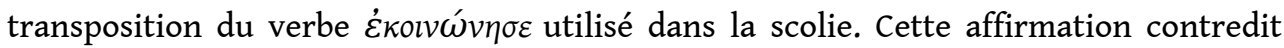
d'ailleurs la version virgilienne, qui s'en tient à l'orthodoxie homérique en rappelant que c'est Diomède qui a tué Dolon ${ }^{52}$.

Les mensonges d'Ulysse étaient d'ailleurs déjà identifiés par les scoliastes : dans l'Iliade, au retour des deux guerriers, Nestor interroge sur la mission, non pas Diomède, chef de l'expédition, mais Ulysse $(10,558-563)$ et les scholies justifient ce point par le fait qu'Ulysse est plus intelligent que Diomède ${ }^{53}$. Dès l'époque alexandrine, Ulysse est donc sélectionné comme le narrateur privilégié de la Dolonie ; mais les scolies elles-mêmes mettent en doute l'absolue sincérité de l'Ulysse narrateur, soupçonné de vouloir embellir l'action nocturne : à Nestor, le fils de Laërte raconte tout d'abord le meurtre de Rhésos et des Thraces ainsi que la capture des chevaux puis le meurtre de Dolon, inversant ainsi l'ordre chronologique des événements, ce qui entraîne le commentaire suivant :

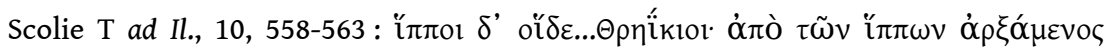

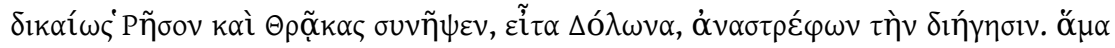

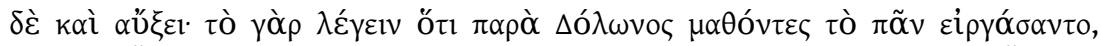

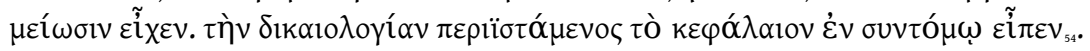


Ulysse dissimule par ailleurs le relatif échec de la mission nocturne en tant que mission d'espionnage, échec que les scoliastes soulignaient implicitement; Aristarque voulait ainsi supprimer une partie des questions qu'Ulysse posait à Dolon sur les intentions des Troyens, sous prétexte que Dolon n'y répond pas par la suite ${ }^{55}$, Iliade 10, 409-411 (= 208-211) :

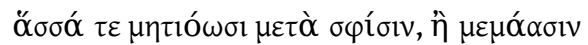

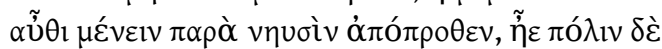

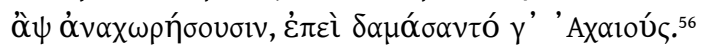

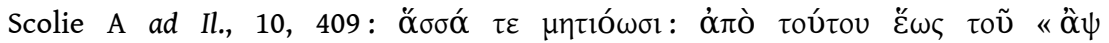

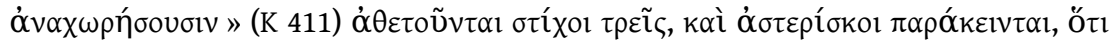

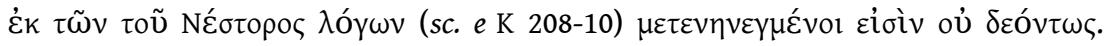

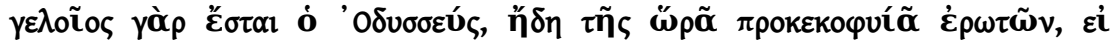

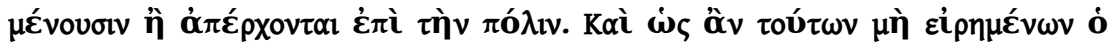

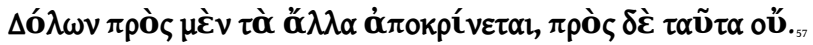

Schlunk et Schmit-Neuerburg, signalant l'influence de cette scholie sur l'épisode de Nisus et Euryale qui oublient eux aussi leur mission première, ont montré que Virgile avait réutilisé cet oubli de la mission comme élément de sa narration; le motif de l'abandon de la mission première se trouve ainsi thématisé chez Virgile : ses héros oublient le but de leur sortie nocturne parce qu'ils sont attirés par un butin facile à faire ${ }^{58}$. Qu'en est-il chez Ovide ? Cet échec de la mission de renseignement, Ulysse la dissimule dans les Métamorphoses (13, 245-247), mais avec une insistance suspecte :

Dolona

Interimo, non ante tamen quam cuncta coegi

Prodere et edidici quid perfida Troia pararet.

Omnia cognoram nec quod specularer habebam ${ }^{59}$.

Ulysse souligne avec insistance le succès de la mission d'espionnage. La redondance est ici trop marquée pour n'être pas suspecte, il s'agit d'une véritable Alexandrian footnote, l'allusion au problème homérique procède à l'aide de véritables marqueurs et souligne le mensonge d'Ulysse. Il est par ailleurs notable que l'emploi du verbe speculor rappelle l'appellation même parfois donnée à la Dolonie homérique par exemple dans la scholie

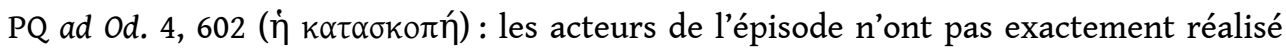
leur programme.

Les divergences ovidiennes par rapport au modèle homérique ont été analysées comme procédant d'une variante mythique antique ${ }^{60}$ ou comme relevant d'une déformation élégiaque ${ }^{61}$. Cette interprétation élégiaque vaut à l'évidence pour le passage de l'Ars et celui de l'Héroïde, mais elle reste inopérante pour les Métamorphoses. Il s'agit en fait de trouver l'origine de cette variation, qui n'est que partiellement élégiaque, dans l'exégèse homérique et les problèmes que posaient l'épisode à la critique. Il semble ensuite que les problèmes homériques, reposant sur de légères incohérences narratives, aient été l'occasion pour Ovide d'opérer, non pas comme les luseis, solutions alexandrines, une réduction des problèmata, mais un effort pour penser la personnalité littéraire ambiguë d'Ulysse dans l'Iliade là où les Alexandrins tentaient à toute force à donner des solutions moralement satisfaisantes aux problèmes. Dès lors, la version non canonique de la Dolonie ovidienne s'avère une variante d'origine exégétique, une explication d'Homère, une lusis qui opère, non plus au niveau de tel ou tel problème localisé, mais comme interprétation globale du personnage épique. La caractérisation du personnage prend ici, et il y a d'autres exemples, appui sur les commentaires. L'Ulysse ovidien est en partie celui des scoliastes. On a là, comme ailleurs chez Ovide, 
un modèle d'intégration dans la narration des données fournies par les commentaires philologiques, une version quelque peu iconoclaste dont le but est d'exhiber le caractère du fandi fictor Ulixes.

\section{Virgile : la fuite à pied de Nisus et Euryale}

C'est également la présence des chevaux lors de la sortie de nuit de Nisus et Euryale qui va retenir notre attention : à l'inverse de ce qui se passe chez Ovide, où on se dispute pour partir à cheval, les deux héros troyens vont fuir à pied, renonçant curieusement à s'emparer des chevaux des Latins qui sont pourtant à leur disposition (9, 351 sqq.) :

Iamque ad Messapi socios tendebat ; ibi ignem

deficere extremum et religatos rite uidebat

carpere gramen equos, breuiter cum talia Nisus

(sensit enim nimia caede atque cupidine ferri) :

« Absistamus, ait, nam lux inimica propinquat.

Poenarum exhaustum satis est, uia facta per hostis. $»^{62}$

Le motif des chevaux se trouve évoqué en creux dans l'épisode virgilien le plus proche de la Dolonie homérique : l'aristie de Nisus et Euryale ; les coursiers sont bien présents dans la Nyctegresia virgilienne, mais précisément, ces chevaux qui comptent tant dans la Dolonie, dans sa version homérique, dans sa version virgilienne, telle qu'elle est représentée sur les murs du temple de Junon, dans sa version euripidéenne et dans sa version ovidienne, ces chevaux sont seulement évoqués ${ }^{63}$; Virgile achemine délibérément ses héros auprès des chevaux et rapproche ainsi au maximum leur situation de celle d'Ulysse et Diomède dans la Dolonie, mais c'est pour mieux marquer l'inflexion différente que prend son récit. Virgile a fait de ses deux héros les émules de Diomède et d'Ulysse pour ensuite, dans un retournement de fortune, leur faire subir le sort de Dolon, qui fuit à pied devant Diomède et Ulysse ${ }^{64}$.

Marco Fucecchi a indiqué combien le fait que les chevaux soient à la pâture avait d'importance par rapport à la représentation de la Dolonie sur les murs du temple de Junon à Carthage. Mais, du point de vue de l'organisation de la narration, un autre point est essentiel ; en interdisant à ses héros de capturer les chevaux des Latins, tout se passe comme si le poète évitait l'épisode homérique qui constituait l'exploit essentiel d'Ulysse et de Diomède. Comme dans les cas de la confrontation avec Polyphème ou Circé, par exemple, Virgile amène son héros à proximité de l'épisode homérique, pour adopter spectaculairement un scénario tout différent. Il ne sera pas ici question de la signification morale que peut revêtir une telle différenciation ${ }^{65}$ qui entre de toute façon en ligne de compte dans l'élaboration d'un épisode tragique ${ }^{66}$. L'erreur fatale que constitue le renoncement à la prise des chevaux se trouvera implicitement soulignée par Virgile lorsque les deux amis seront rejoints par les Latins, bien sûr, à cheval : Nisus entendra d'abord... des chevaux (394: audit equos), en un ironique retournement ; dans le Rhésos, Ulysse et Diomède entendent les chevaux avant de voir le camp des Thraces (565-569).

31 Examinons le déroulement de cette fuite à pied. On l'a dit, l'aristie de Nisus et Euryale leur fait assumer successivement le rôle d'Ulysse et Diomède puis celui de Dolon, capturé dans la nuit troyenne par les deux Grecs ${ }^{67}$. Les deux héros virgiliens, après avoir perpétré un massacre, continuent leur route à pied, chargés du butin qu'ils ont pris chez leurs victimes . Lorsqu'ils sont surpris par l'ennemi, leur réaction s'apparente 
nettement à celle de Dolon, comme l'a noté Philip Hardie ${ }^{68}$. Nisus et Euryale entrent dans une forêt (378), alors qu'Ulysse et Diomède sont comparés dans Homère à des chiens poursuivant un lièvre dans une forêt $(10,360-362)$. Les deux Grecs coupent le chemin de Dolon, de même que les Latins coupent toute retraite à Nisus et Euryale.

Le texte virgilien se calque donc exactement sur la poursuite de Dolon par Ulysse et Diomède. Mais la raison pour laquelle le fuyard est rejoint se trouve, dans les deux cas, différente. Si c'est l'impulsion donnée par Athéna qui permet à Diomède de s'emparer de Dolon, Euryale, quant à lui, est retardé par l'obscurité des bois et le poids du butin dont il s'est emparé (9, 383-384) :

Euryalum tenebrae ramorum onerosaque praeda

Impediunt. ${ }^{69}$

Ce motif de la fuite entravée par le butin est absent de la capture de Dolon dans l'Iliade. Le texte homérique insiste au contraire sur la rapidité de l'homme et ses adversaires ne doivent de le capturer qu'à l'intervention d'Athéna (365). La fuite entravée peut, bien sûr, être un motif purement virgilien. Il se trouve toutefois que le scénario de la course gênée par le butin se trouve évoqué dans le commentaire exégétique d'Eustathe (820, 59) et qu'il a toute chance de remonter à l'époque alexandrine ${ }^{70}$. Il s'agit toujours de démontrer qu'Ulysse, comme Diomède, était bien à cheval cette nuit là ; si tel n'avait pas été le cas, Diomède ne lui aurait pas donné à porter le butin constitué par les dépouilles de Dolon:

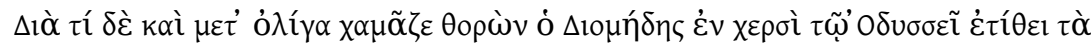

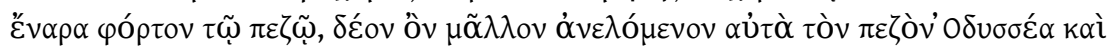
$\tau \tilde{\imath}$ i i $\pi$ ót

Ce scénario impossible de la fuite à pieds d'Ulysse chargé des dépouilles de Dolon aux côtés de Diomède à cheval apparaît chez Eustathe comme une preuve du fait qu'Ulysse est lui aussi à cheval. Mais tout se passe comme si le scénario de la fuite à pied de Nisus et Euryale, entravés par le butin, se trouvait en germe dans les ratiocinations des interprètes d'Homère. En outre, comme le fait remarquer Philipp Hardie, ce scénario de la fuite à pied se trouve en quelque sorte surdéterminé par la course à laquelle prennent part Nisus et Euryale au chant 5 . Ce qui confirme de manière singulière ce rapprochement, c'est que l'on retrouve intégrée à l'évocation d'Euryale lors de cette course une partie du raisonnement rapporté par Eustathe et que cette solution est reprise de manière encore plus probante dans la Thébaïde de Stace, où l'un des deux héros de la Nyctegresia du chant 10, Dymas, a lui aussi participé à la course à pied lors des jeux du chant 8 :

Eustathe, 820, 59, ad Il. 10, 499 ; si Ulysse n'était pas monté à cheval, il aurait dû avoir des ailes aux pieds :

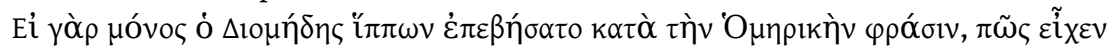

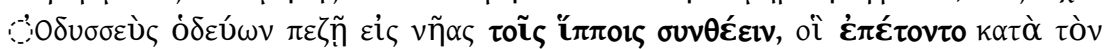

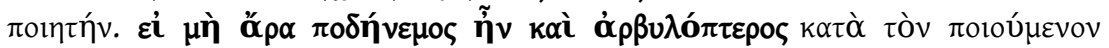

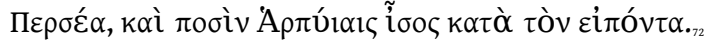

Répondant par avance à une objection de ce type, le texte virgilien fait d'un des futurs fuyards de sa Nyctegresia un coureur remarquable en recourant aux hyperboles traditionnelles en pareil cas $(5,318-319)$ :

Primus abit longeque ante omnia corpora Nisus emicat et uentis et fulminis ocior alis ${ }^{73}$. 


\section{(Thébaïde, 6, 558) :}

Alipedumque fugam praegressus equorum

ante Dymas, sed nunc aeuo tardante secutus. ${ }^{74}$

Le motif de l'aile, voire, plus précisément chez Stace, celui des pieds ailés, se trouve repris dans les deux textes latins. Tout se passe en fait comme si, en adoptant le scénario que certains critiques antiques considéraient comme une interprétation impossible du texte modèle, Virgile avait choisi d'intégrer discrètement au chant 5 la solution « merveilleuse », la réactivation discrète du modèle de Persée, reposant sur les hyperboles épiques, de façon à justifier a priori la fuite à pied des héros lors de la Nyctegresia. ${ }^{75}$

Il est intéressant de constater que le scénario virgilien semble ici issu non pas du texte homérique mais d'une de ses interprétations contestées. Le scénario de la fuite à pied trouve dans l'Enéide une consécration en devenant l'occasion de l'aristie de Nisus et Euryale. Or ce schéma narratif est-il rien d'autre, à l'origine, que l'hypothèse d'un raisonnement exégétique? La réécriture d'Homère s'inscrit ici dans une perspective toute différente de celle proposée par Alessandro Barchiesi dans La Tracia del modello (p. 33), à propos de la reprise d'éléments topiques du genre épique qu'il décrit comme «mécanisme de signification à haut rendement narratif d'autant plus efficace que le texte auquel il est fait allusion est codifié ». On se trouve avec la Dolonie tout entière, dans le cadre d'un récit atypique qui ne correspond pas aux exploits traditionnels de l'épopée. Il n'y a pas là la reprise d'éléments topiques diffus de la tradition épique mais bien une utilisation particulièrement précise de type alexandrin du matériau exégétique proposé par les lectures hellénistiques. L'exemple de la fuite à pied illustre d'une manière frappante, pour employer une métaphore philologique, une sorte d'interpolation de la glose marginale dans le texte, une espèce d'interpénétration entre le commentaire et la fiction.

\section{Haud temere est uisum}

Nisus et Euryale vont être aperçus dans la nuit par leurs ennemis et cet épisode se calque, comme on le sait, sur la surprise de Dolon par Ulysse et Diomède. Là encore, l'influence des scholiastes se fait sentir sur le texte virgilien. Robin Schlunk et Tilman Schmit-Neuerburg ont déjà traité partiellement cette question ${ }^{76}$, mais je crois possible de préciser un peu les choses en les abordant sous un angle légèrement différent.

Dans l'Iliade, Diomède revêt un casque en peau de taureau, sans cimier ni panache. Les commentateurs anciens justifient cette scène d'armement atypique par la nécessité du camouflage: le combat de nuit exige un équipement approprié et des armes qui permettent de ne pas se faire repérer par l'ennemi ${ }^{77}$. On a remarqué ${ }^{78}$ qu'à ce casque mat s'opposait le casque brillant dont Euryale s'empare dans l'Enéide (galeam Messapi nitentem) et qui allait causer sa perte dans le chant 9 (373-375) :

Et galea Euryalum sublustri noctis in umbra

prodidit immemorem radiisque aduersa refulsit.

Haud temere est uisum.

41 C'est ainsi qu'Euryale est repéré par l'ennemi. Or, ce motif de la fulgurance des armes sous la clarté nocturne est, comme l'a noté Hopkinson, emprunté aux cycliques ${ }^{79}$; l'épisode s'inspire de la Petite Iliade : Ulysse et Diomède se sont emparés du Palladium et 
s'enfuient, de nuit, vers le camp achéen. Ulysse, toujours perfide, veut s'approprier l'objet et la gloire de le ramener au camp ; il lève son épée pour frapper Diomède, mais le métal luit à la clarté de la lune, qui est alors levée et permet à Diomède d'éviter le coup $^{80}$. Dès lors, l'adjectif immemor pourrait bien revêtir la valeur métatextuelle d'un renvoi à la Petite Iliade. Euryale ne se souvient plus de la mésaventure arrivée à Ulysse, plein de convoitise pour un butin nocturne lors du rapt du Palladium et, comme lui, trahi par la lune. On notera que le motif de la fulgurance des armes est repris chez Ovide. Lorsqu'Ajax raille l'incapacité d'Ulysse à assumer l'armement d'Achille, il l'imagine, lui qui aime à agir de nuit, trahi par la rutilance du casque d'Achille. A l'inverse d'Euryale, Ajax se souvient de la Petite Iliade et de l'Enéide (13, 105-106):

Ipse nitor galeae claro radiantis ab auro insidias prodet manifestabitque latentem.

Les termes insidias et latentem réactivent le prototype de Dolon, qui est, réellement, le prototype caché de toutes ces sorties de nuit.

Revenons sur les circonstances dans lesquelles Dolon est repéré par Ulysse et Diomède au cours du chant 10 de l'Iliade. Lorsqu'Ulysse signale à Diomède la présence de Dolon, les commentateurs s'interrogent: comment Ulysse a-t-il pu se rendre compte de la présence de Dolon dans l'obscurité, alors que peu auparavant, il n'avait pourtant pas $\mathrm{vu}$, mais seulement entendu le héron que leur envoie Athéna $(10,276)^{81}$. Et pourtant il perçoit la présence de Dolon $(10,339-340)^{82}$. Le problème est posé de la manière suivante:

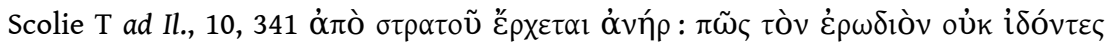

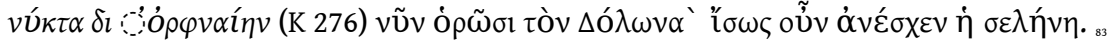

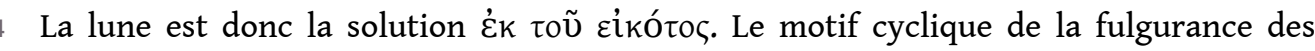
armes à la clarté lunaire se trouve intégré à l'imitatio virgilienne de l'épisode iliadique pour résoudre le problème. Mais il n'y a pas là qu'un simple « remploi d'antique ». On voit que Virgile intègre la lusis avec un certaine insistance - la redondance, là encore espèce d'Alexandrian footnote, signalant l'allusion au cas de Dolon ou au scénario de la Petite Iliade, à travers l'oxymore sublustri noctis in umbra et le terme radiis ${ }^{84}$.

5 Mais surtout, la formule haud temere est uisum semble comme un commentaire philologique de l'opération ; la tournure est vraisemblablement à prendre au pied de la lettre, en opposition à l'expression homérique $v v_{\kappa} \tau \alpha \delta_{l}$ ó $\rho \varphi v \alpha i ́ \eta v$, avec jeu de mot sur le sens étymologique de temere, ablatif instrumental de l'inusité *temus, temeris ${ }^{85}$ : on n'a pas vu, à l'aveuglette ou à travers les ténèbres ${ }^{86}$. Ce qui confirme ce jeu étymologique, c'est que cette expression apparaît comme la traduction littérale d'une tournure homérique :

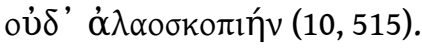

Tout d'abord, les deux expressions sont employées au moment où, dans les deux textes, commence la fuite des héros de la sortie nocturne, et le parallélisme des deux narrations paraît une garantie suffisante de l'intention allusive. Dans l'Enéide, c'est alors que Nisus et Euryale voient approcher la «lumière ennemie » $(9,355)$ et tentent de rejoindre le camp des Troyens qu'ils sont aperçus par Volcens et les cavaliers latins. Dans la Dolonie, c'est au moment où Diomède et Ulysse s'enfuient avec les chevaux de Rhésos pour regagner le camp achéen $(10,512-514)$ : c'est alors qu'Apollon voit Athéna seconder Ulysse et Diomède et réveille les Thraces pour qu'ils se lancent à la poursuite des deux assaillants: Apollon n'a pas monté la garde en aveugle. Une scholie revient précisément sur l'étymologie de cette expression: 


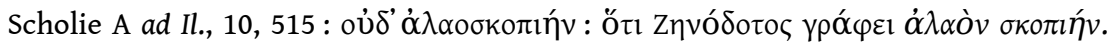

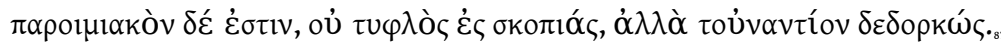

\section{plus exactement qu'une lumière hostile approche : iam lux inimica propinquat. Or, cette} lumière hostile aux Troyens, qui cherchent dans leur fuite l'obscurité des bois (378: fidere nocti) démarque, semble-t-il une partie du commentaire exégétique homérique, là encore fourni par le seul Eustathe ${ }^{90}$, qui interprète ainsi le moment crucial où les héros sont obligés de fuir plutôt que de continuer leur sanglant pillage dans le camp thrace $(821,33)$ :

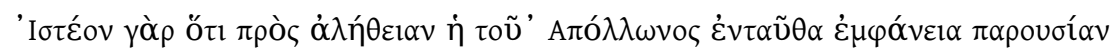

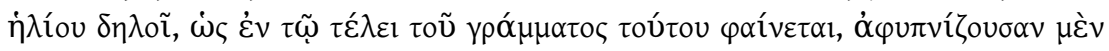

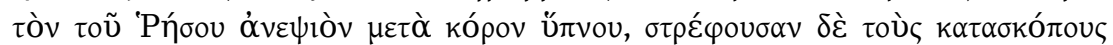

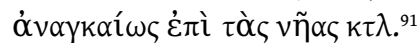

51 Si l'intervention d'Apollon signifie le lever du soleil, dès lors, les deux expressions,

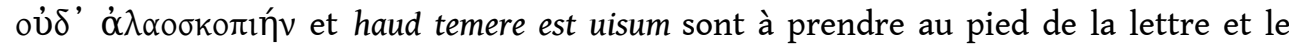
lever de l'astre marque l'apparition d'une lumière hostile aux Grecs dans un cas, aux Troyens dans l'autre ${ }^{92}$. Virgile souligne ainsi pleinement la cohérence retrouvée du motif et l'opération philologique permettant de rétablir la vraisemblance de cette vision nocturne. Le motif homérique se trouve ici retravaillé à l'aide de la lusis alexandrine et le problème narratif qui existait chez Homère est supprimé.

La portée d'une telle opération est difficile à déterminer. Comme pour ce qui se passe dans le cas de la fuite à pied, il s'agit en un sens de produire un scénario qui souligne nettement ses parallélismes avec la narration homérique pour mieux marquer une inflexion différente, tout en exploitant les ressources des lectures alexandrines; à l'occasion d'une étymologie savante, le récit virgilien souligne une dernière fois sa parenté avec le modèle homérique avant de prendre un tour tragique à travers la mort des deux héros de la Nyctegresia. Le décalque érudit est ainsi comme l'ultime point de contact entre les deux scénarios épiques.

\section{Conclusion}

Les scénarios imaginés par Ovide et Virgile trouvent en partie leur origine dans les lectures alexandrines de la Dolonie; mais au-delà de simples jeux philologiques, Ovide met en scène un fictor fandi Ulixes que les exégètes alexandrins ont déjà découvert dans le récit fait à Nestor à la fin de la Nyctegresia. Cet Ulysse est, bien évidemment, à cheval. À l'inverse, Virgile, partant du même problème homérique, met ses héros à pied, en 
adoptant pour sa sortie de nuit un scénario qui paraissait impossible aux Alexandrins. L'exploitation de la philologie homérique trouve là sur un même problème deux expressions opposées dont l'écart est difficile à évaluer. La version ovidienne, qui tend à mettre en relief les problèmes posés par le texte homérique, semble, somme toute, plus facile à interpréter, dans la perspective d'une réflexion sur le personnage d'Ulysse. La démarche virgilienne est plus complexe. En un sens, sur certains détails, comme celui de la vision nocturne, Virgile corrige le texte modèle, en recourant si besoin à un matériau narratif emprunté à la tradition cyclique qui lui permet de lisser les aspérités de la narration homérique et procure une sorte d'epos en progrès, qui intègre des solutions proposées par les commentateurs (en l'occurrence, l'hypothèse du lever de la lune proposée par les scolies pour résoudre le problème de la vision nocturne). On va vers un scénario amendé, purgé de ses incohérences. Mais à côté de cela, le texte virgilien opère des choix qui peuvent paraître à leur tour problématiques au regard du modèle : pourquoi Nisus et Euryale fuient-ils à pied, chargés de butin, en pays ennemi, alors qu'ils avaient l'occasion de s'emparer des chevaux des Latins, alors précisément que la lecture alexandrine d'Homère excluait un tel scénario pour la Dolonie homérique? L'enjeu est bien évidemment d'ordre poétique et le continuum tragique instauré par le refus de prendre les chevaux des Latins aboutit à la catastrophe finale. Ce que l'on a voulu souligner concerne avant tout le processus complexe d'élaboration d'une narration à partir de l'exégèse du texte modèle.

\section{BIBLIOGRAPHIE}

BARCHIESI A. : La traccia del modello. Effetti omerici nella narrazione virgiliana. Pise, 1984.

P. Ovidii Nasonis Epistulae Heroidum 1-3 a cura di Alessandro BARCHIESI, Felice Le Monnier Firenze, 1992

BÖMER F., P. Ovidius Naso, Metamorphosen. Kommentar von Franz Bömer. Buch XII-XIIII, Carl Winter Universitätsverlag, Heidelberg, 1982.

CARroll Mitchel: Aristotle Poetics, C. XXV, in the light of the Homeric Scholia, thèse de la John Hopkins University, Baltimore, 1895.

Cirio A. M. : Lettura di Omero : Canto X dell'Iliade. Bibliotheca Phiologica, L'Epos, Palerme, 1998.

ERBSE H.: Scholia Graeca in Homeri Iliadem (Scholia Vetera), Berlin, 1969-1988.

ERnout A., MeIllet A. : Dictionnaire étymologique de la langue latine, $4^{\mathrm{e}}$ édition (revue et augmentée par J. André), Klincksiek, Paris, 1985.

FuCECCHI Marco : “'Cavalli al pascolo’ nella notte di Eurialo e Niso », Rivista di Filologia 127, 1999, p. 206-22.

GALLET DE SANTERRE Hubert : «Ulysse meurtrier de Dolon » in mélanges offerts à Octave et Melpo Merlier, tome 1, Athènes, 1956, p. 228-234. 
GIANNANTONI G. : Socratis et Socraticorum reliquiae, collegit, disposuit, apparatibus notisque instruxit G. Giannantoni, Elenchos, vol. 18.4-18.5, 1991.

HAINSWORTH J.B.: The Iliad. A Commentary, vol. 3 (9-12), Oxford, 1991.

HARDIE Philip: Virgil. Aeneid. Book IX, edited by Philip Hardie, Cambridge, 1994.

HEFFERNAM: Museum of words. The poetics of ekphrasis from Homer to Ashbery, Chicago, The University of Chicago Presse, 1993.

HopkInson Neil: Ovid. Metamorphoses. Book XIII, edited by Neil Hopkinson, Cambridge, 2000.

JANKA Markus: « Ovid Ars amatoria. Buch 2. Kommentar », Heidelberg, 1997.

LABATE Mario: « Ulisse, Eurialo e le armi di Achille (Ov. Met. XIII, 98 sgg.) », Atene e Roma 25, 1980, p. 28-32.

McKeown J.C.: Ovid : Amores. Text, Prolegomena and Commentary in four volumes. Volume II. A commentary on book one. Leeds, 1989.

O'HARA James J.: Death and the otpimistic prophecy in Vergil's Aeneid, Princeton, 1990.

True Names. Vergil and the Alexandrian Tradition of Etymological Wordplay. Ann Arbor, University of Michigan, 1996.

PALMER Arthur, PURSER L.C., P. Ovidi Nasonis Heroides with the greek Translation of Planudes, Oxford, 1898.

PFEIFFER R.: History of Classical Scholarship from the Beginnings to the end of the hellenistic Age, Oxford, 1968.

PUTNAM M.C.J.: « Dido's murals and Virgilian ekphrasis », Harvard Studies in Classical Philology 98, 1998, p. 243-275.

RICHARDSON N.J. « Literary criticism in the exegetical scholia to the Iliad : a sketch », CQ n. s. 30, 1980 , p. 265-287.

SCHLUNK Robin R., The Homeric Scholia and the Aeneid. A Study ot the Influence of Ancient Homeric Literary Criticism on Vergil, Ann Arbor, The university of michigan Press, 1974.

SCHMIT-NEUERBURG Tilman: Vergils Aeneis und die Antike Homerexegese. Untersuchungen zum Einfluß ethischer und kritischer Homerrezeption auf imitatio und aemulatio Vergils , Berlin, New York, 1999.

SHARROCK Allison R. Ars Amatoria 2.132-42: « Another Homeric Scene in Ovid. Mnemosyne 40, 1987, p. 406-412.

SEVERYNS Albert : Le cycle épique dans l'école d'Aristarque, Liège-Paris, 1928.

VAN DER VALK M.: Researches on the Text and Scholia ot the Iliad, Leyde, 1, 1963.

- Eustathii archiepiscopi Thessalonicensis Commentarii ad Homeri Iliadem pertinentes, Leyde, 1971-1987.

WiLLIAMS M.F.: « Crossing into Enemy Lines: Military Intelligence in Iliad 10 and 24 », Electronic Antiquity, Virginia Polytechnic and State University, V, 3, 2000.

WiLLIAMS R.D., « The pictures on Dido's temple », CQ 10, 1960, p. 141-151. 


\section{NOTES}

1. La capture des chevaux de Diomède était particulièrement importante parce qu'elle était liée à la prise de Troie, selon certaines traditions: Schol. AD ad Il., 10, 435 et Servius ad Aen., 1, 469 : abductique sunt equi, quibus pendebant fata Troiana, ut, si pabulo Troiano usi essent vel de Xantho Troiae fluvio bibissent, Troia perire non posset.

2. Enéide, 1, 469 sq.

3. Il ne s'agit pas, selon Williams R.D., p. 148, de la lance d'Achille qui aurait transpercé Troïlos, mais ce dernier usait du bout de sa lance retournée pour aiguillonner ses chevaux, sur le modèle de ce que font les Rutules pour pousser leurs troupeaux (cf. En., 9, 609-610: uersaque iunencum / terga fatigamus hasta).

4. Putnam, p. 259.

5. Heffernam, p. 28-29: «the scribble of the spearhead at once mirrors the tragedy of Troy and the trace left by the tragedy, etc. ».

6. Art d'Aimer, 2, 131-132.

7. Dans les deux cas, la baguette d'Ulysse et la lance de Troillus sont détournées de leur fonction première : la baguette sert à construire le radeau, la lance de Troïle est retournée parce qu'il s'en est servi pour pousser ses chevaux.

8. Enéide, 1, 751 sqq.

9. Voir Schlunk, p. 59-81, et Schmit-Neuerburg, p. 23-65.

10. La prégnance du modèle homérique pour ce dernier épisode était d'ailleurs un fait bien identifié chez les lecteurs antiques. Voir la comparaison de la Dolonie et de l'épisode virgilien dans l'Ibis, 625 sqq.; Macrobe, 5, 2, 15; 5, 9, 5-11; Servius ad Aen, IX, 1. Cf. Schmit-Neuerburg, p. 24-25.

11. Voir McKeown, p. 268 ad 23-24. L'allusion éventuelle à la Dolonie des Remedia, 282 est vraiment vague.

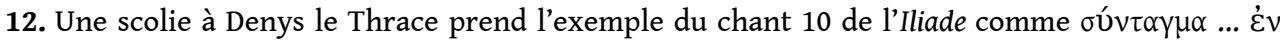

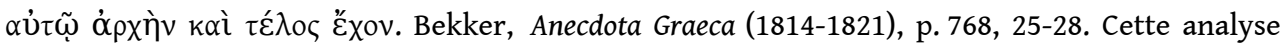
remonte sans doute à l'école péripatéticienne (cf. Cirio, p. 19).

13. Scholie $\mathrm{T}$ ad 10,1 (cf. Eustathe 785,41 ): «On dit que ce chant a été composé isolément par Homère et qu'il ne constituait pas une partie de l'Iliade, mais qu'il a été placé dans le poème par Pisistrate ». Voir Cirio, p. 11 sq. pour un état de la question.

14. C'est toujours un des thèmes de la critique du chant 10 ; on trouvera un état de la question avec une abondante bibliographie dans Williams M. F. ; la Dolonie met entre autres en valeur la ruse d'Ulysse ; mais on a pu souligner la traîtrise d'Ulysse et Diomède qui tuent Dolon après lui avoir promis la vie sauve. Par ailleurs, il s'agit d'une aristie atypique qui a lieu de nuit. C'est le seul cas d'acte guerrier nocturne dans l'Iliade. L'exploit se distingue nettement des aristies homériques traditionnelles: le combat iliadique type a lieu en plein jour, dans le cadre d'un combat singulier, à la loyale, sous les yeux de toute l'armée, ce qui permet d'acquérir la gloire. Dans cette perspective le massacre de Dolon, de Rhésos et des Thraces peuvent sembler manquer d'héroïsme.

15. Ce problème est abondamment souligné chez les commentateurs modernes. Les scholies ne portent pas de trace explicite de ce débat, se contentant de valoriser Ulysse, même si un certain nombre d'entre elles évoquent la question de sa lâcheté. Ulysse est bien sûr le héros achéen le plus problématique : les légendes cycliques rapportent ses démêlées avec Palamède, etc., mais les textes homériques eux-mêmes comportent un certain nombre d'ambiguïtés que soulignent les scholies (e. g. bT 7, 168 ; AbT, 8 , 97 sqq., 226 ; AbT 10, 139-140 ; T 10, 149). Voir Richardson, p. 273. On notera aussi que le texte homérique signale le massacre de Rhésos et des siens comme

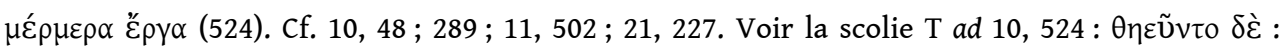

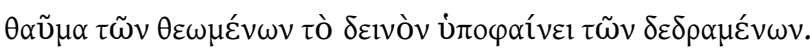


16. Voir Schmit-Neuerburg, p. 54 sq. La retractatio virgilienne fait apparaître au grand jour les questions éthiques posées par les commentateurs antiques à propos de l'épisode homérique.

17. Cf. Giannantoni, 18.4, p. 332, fr. VIII.6. Antisthène était un grand homériste. Selon Diogène Laërce (6, 17 sqq.), le tome 8 de ses œuvres était consacré à l'Iliade et le tome 9 à l'Odyssée. Un des

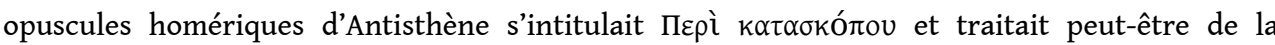
Dolonie, à moins qu'il n'y fût question de la Ptocheia. Le terme kataskopos se trouve employé pour les deux épisodes, par exemple par Proclus, Chrest., 206 Severyns, au sujet de la Ptocheia et au

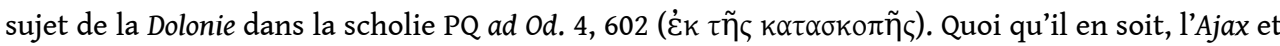
l'Ulysse associent visiblement les différents exploits d'Ulysse devant Troie.

18. Selon les éditeurs, c'est Agamemnon qui diminue la valeur de Diomède et Ulysse.

19. «Ces valeureux guerriers <sc. Ulysse et Diomède> ont été guidés par leur seule vaillance ; or toi, tu diminues leur gloire ».

20. Aristarque, constatant qu'Homère ne mentionnait pas l'équitation dans le poème, faisait de cet usage un élément de différenciation entre la poésie homérique et celle des kuklikoi. Severyns, p. 128 : «En somme, Aristarque essayait de mettre en lumière ce fait que les héros homériques ne sont point des cavaliers et la remarque acquiert une certain importance si l'on se souvient que Troille s'exerçait à l'équitation, dans les Chants Cypriens, et que les Amazones combattaient à cheval , dans l'Ethiopide.»

21. Pour certains commentateurs anciens, il y a là un anachronisme. Cf. Scolie T ad $\mathrm{O} 679$.

22. Voir Putnam, p. 259.

23. «Le premier les interrogea Nestor de Géréna, dompteur de chevaux : 'Allons, dis-moi, illustre Ulysse, grande gloire des Achéens, comment avez-vous pris tous deux ces chevaux?'« Noter l'emploi du duel qui associe d'emblée Ulysse à la prise des chevaux.

24. Scholie bT ad 10, 568.

25. Ainsi, dans l'Odyssée, Télémaque refuse-t-il les chevaux que lui offre Nestor, arguant de la difficulté de les faire vivre à Ithaque. En 11,488, le scoliaste signale que c'est sur son char que Ménélas emmène Ulysse, en effet celui-ci, habitant d'une île, ne connaît pas les chevaux. Voir

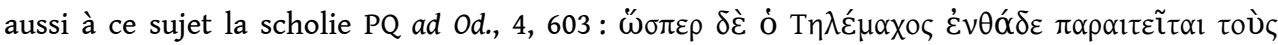

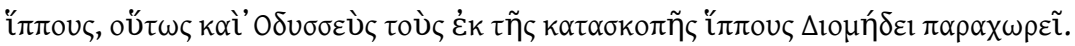

26. Scolie $\mathrm{T}$ ad 568 .

27. Une partie de la tradition exégétique, rapportée dans les scolies $A$, semble assumer l'idée que

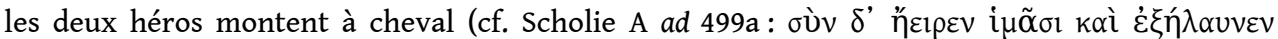

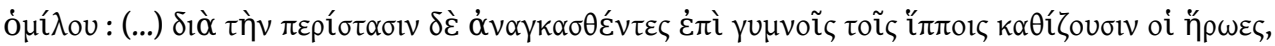

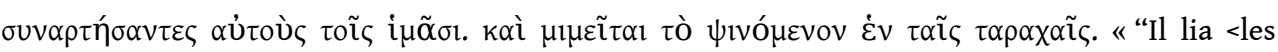
chevaux> bien ensemble et les poussa hors de la masse <des cadavres> " : (...) à cause des circonstances, les héros se trouvent contraints de monter les chevaux à cru après les avoir attachés les uns aux autres avec des courroies. Le poète imite ce qui advient dans les situations urgentes. »

28. «Vivement, il <sc. Diomède> monta sur les chevaux (í $\pi \pi \omega v \dot{\varepsilon} \pi \varepsilon \beta \eta ́ \sigma \varepsilon \tau o$ ) et Ulysse les frappa de son arc : ils s'envolèrent vers les nefs rapides des Achéens ».

29. "Sautant à terre, le fils de Tydée plaça les dépouilles sanglantes entre les mains d'Ulysse et remonta sur les chevaux ".

30. Lors de la tempête de l'Odyssée (5, 370-371), Ulysse enfourche une poutre « comme s'il montait

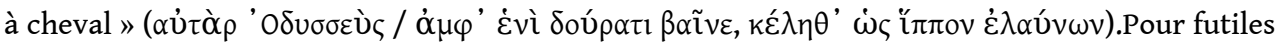
qu'ils paraissent, ces problèmata sollicitent toujours l'acribie des commentateurs; voir Hainsworth, ad 10, 498 sq., p. 202-203.

31. «Le poète connaît l'équitation, mais il ne montre pas les héros faisant usage de cette pratique, si ce n'est, sous l'effet de la nécessité, Diomède dans la Dolonie. » Cette remarque est reprise par Eustathe dans des termes proches en 1539, 31. Voir également les scolies ad Il., 15, 679 et 10, 499 ( $a d$ verbum keletizein) et Eustathe 1037, $59(15,680)$. 
32. La classification des solutions aux problèmes homériques remonte à Aristote. Elle a été reprise par les Alexandrins. Voir l'exposé de Caroll, qui, bien qu'ancien, présente l'avantage d'être systématique.

33. « Noter que (...) Diomède et Ulysse montèrent tous deux à cheval. Cela est clair d'après le vraisemblable: si seul Diomède était monté à cheval, conformément à la lettre du texte homérique, comment Ulysse aurait-il pu, à pied, courir jusqu'aux nefs à côté des chevaux qui, à ce que dit le poète, volaient (...) ? Mais surtout le récit se révèle plus exact dans ce que dit le poète ensuite : ils mirent pied à terre (513). C'est donc qu'ils sont montés tous les deux à cheval, ce qui fait que dans l'expression Diomède monta vite à cheval, il faut comprendre en même temps Ulysse, par syllepse. " Erbse, p. 107 ad 10, 513, et Van der Valk (ad Eustat. 820, 59 sqq.) semblent considérer que ce problème homérique, un peu naïf, était posé par Eustathe lui-même et ne remontait donc pas à l'exégèse alexandrine, mais la comparaison avec la scolie PQT ad Od. 5, 371 citée plus haut confirme le caractère antique, sinon de la solution, au moins du problème. Il est vraisemblable qu'Eustathe avait accès à des sources plus importantes que les seules scholies qui nous sont parvenues. Van der Valk (1963 p. 86 sq. et 1976-1987, 1, préface, p. LX sq.) pense qu'Eustathe disposait d'une documentation correspondant à peu près à nos scholies. Erbse, 1, 1969-1988, préface, p. LI sq., est d'une opinion différente, de même que Pfeiffer, p. 240.

34. D'un point de vue mythographique, les liens de Diomède avec les chevaux sont très nombreux. Voir RE art Diomedes 1) (Bethe) col. 815 sqq., passim et il en demeure une trace nette dans l'Enéide puisque le héros passe pour avoir fondé la ville d'Argyrippa, à l'origine "Argos Hippion ». Voir Servius ad Aen. 11, 246; O'Hara, p. 230. Au chant 10, 581-582, il est encore question des fameux chevaux thraces, lorsque Liger apostrophe le héros troyen qu'il s'apprête à combattre : Non Diomedis equos nec currum cernis Achilli / aut Phrygiae campos.

35. Scolie bT ad 10, 568 .

36. Cette thèse de la supériorité de Diomède a été exploitée dans la tragédie par Théodecte, au témoignage d'Aristote, Rhétorique, 2, 23, 1399 b 28 ( = TGF 72 F1 Snell).

37. "'Le bon Diomède a tué leur chef': Ulysse ne s'est pas même impliqué dans le vol des chevaux "

38. Palmer, p. 282 ad Her. 1, 46 avec plusieurs exemples, complété par Barchiesi (1992), ibid.

39. Hainsworth, p. 202 ad 498 sq.

40. Iliade 10, 498; Hainsworth, p. 203.

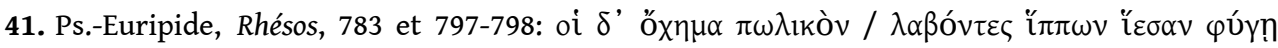
$\pi$ ó $\alpha$.

42. Caroll, p. 49 sq., part. p. 51.

43. L'allusion de Catulle, $58 \mathrm{~b}$ : Rhesi... niueae citaeque bigae, est elle-même ambiguë puisque niueae se rapporte aux chevaux, dont la blancheur est proverbiale, et non pas au char.

44. Sur ces chevaux, cf. Euripide, Hercule 379 sqq.; Alceste, 494 ; Diodore, 4, 15, 3 sqq., etc. On trouve l'ensemble des références dans Bömer, ad Met. 9, 194.

45. «De quelle sorte étaient les chevaux de Diomède: (...) < Didon> l'interroge au sujet des chevaux que <Diomède> a pris à Rhésos. Elle demande « de quel genre » comme si elle demandait s'ils étaient aussi féroces que ceux dont ils tiraient leur origine. En effet Diomède, roi de Thrace possédait des chevaux qui se repaissaient de chair humaine. Ce sont ceux-là qu'Hercule, après avoir tué le cruel tyran, a emmenés, selon la tradition. Et c'est de ceux-là que tirent, dit-on, leur origine les chevaux dont il a été fait mention plus haut ».

46. Voir le curieux récit de Gavius Bassus retranscrit par Aulu Gelle, Nuits Attiques, 3, 9, 1-4: le proverbial cheval de Séius, descendant des chevaux de Diomède le Thrace, qui portait malheur à ses propriétaires et entraînait leur perte. Gnaeus Séius fut ainsi condamné à mort par Marc Antoine.

47. Sur l'attribution à Héraclite, voir Buffière (éd.) : Héraclite, allégories d'Homère, Paris, 1962, p.VIII-IX. 
48. «<Ces cavales> étaient sauvages et errantes; alors que personne ne pouvait les atteler à un char, Héraclès les attela. "

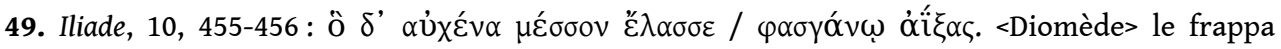
brusquement de son épée au milieu de la gorge et trancha les deux muscles. »

50. « Nous avons pris l'espion»: Ulysse s'est associé au meurtre de Dolon.

51. Cf. Bömer, Hopkinson, ad loc.

52. Enéide, 12, 350-351. Toutefois, Servius, ad Aen. 12, 347 transmet une notice où Diomède et Ulysse tuent Dolon.

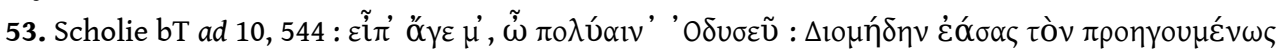

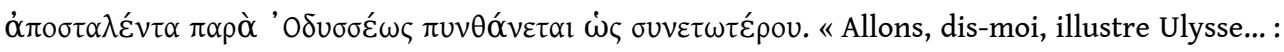
$<$ Nestor> laisse Diomède auquel principalement avait été confiée la mission et s'informe auprès d'Ulysse, parce qu'il est plus intelligent ».

54. «Commençant <son récit> par les chevaux, Ulysse y a justement rattaché Rhésos et les Thraces, puis Dolon, inversant l'exposition des faits. Mais ce faisant, il les amplifie : le fait de dire qu'ils ont tout fait sur les indications de Dolon comportait un amoindrissement <de leurs mérites> ".

55. Le fait que la mission n'est pas remplie n'a pas semble-t-il attiré l'attention de beaucoup de commentateurs. Voir toutefois Hainsworth, p. 207, ad 10, 544-553 et surtout, avec référence à la scholie, Schlunk, p. 75 et Schmit-Neuerburg, p. 54, n. 142.

56. «Qu'est-ce que <les Troyens> méditent dans leur cœur? ont-ils l'intention de rester là, non loin des nefs, ou se replieront-ils vers la ville, après avoir battu les Achéens ?»

57. «'Que comptent faire <les Troyens>' de là jusqu'à 'rentrer chez eux (411)', trois vers sont frappés d'athétèse et on leur adjoint des astérisques, parce qu'il s'agit d'une transposition inutile des paroles de Nestor (sc. e 10, 208-210). Car il sera ridicule qu'Ulysse, alors que l'heure est déjà bien avancée, demande si <les Troyens> restent <sur place> ou retournent dans leur ville. D'ailleurs Dolon répond aux autres questions, mais pas à celles-là, comme si elles n'avaient pas été posées. "

58. P. 75-76: le fait que ses héros cèdent à l'appât du butin les conduirait à leur perte (cf. SchmitNeuerburg, p. 56-57). Voir Eustathe, 820, 52 sq. qui ne relève pas l'abandon de leur mission par Ulysse et Diomède et justifie l'attaque des Thraces .

59. «Je tue Dolon (...) non sans l'avoir cependant contraint à tout me révéler et appris par le menu ce que préparait Troie la perfide. Je savais tout et je n'avais plus de raison de poursuivre ma reconnaissance. "

60. Voir e.g. Gallet de Santerre.

61. Sharrock, p. 409 sq.; Barchiesi (1992), p. 80; Janka, p. 32 sq.

62. « Déjà, Euryale se dirigeait vers les compagnons de Messapus. Là il voyait s'éteindre le dernier feu, et les chevaux paissant dans l'herbe, attachés comme d'habitude, lorsque Nisus intervient brièvement: (car il savait qu'Euryale était emporté par un désir immodéré de carnage). "Arrêtons-nous, dit-il, la lumière du jour, notre ennemie, s'approche. Notre soif de vengeance est satisfaite, notre route tracée à travers les ennemis" ".

63. On peut remarquer par ailleurs que le cheval de Turnus a été promis en récompense à Nisus par Ascagne (Enéide, 9, 269 : uidisti quo Turnus equo etc.) en un motif qui démarque la promesse faite par Hector à Dolon de lui attribuer les chevaux d'Achille (avec quelques différences cependant, voir Schmit-Neuerburg, p. 52).

64. Fucecchi, p. 216 et indications bibliographiques p. 207 n. 2. On remarquera que dans le Rhésos du Pseudo-Euripide (210-214), Dolon projette de marcher à quatre pattes, comme un loup, lorsqu'il approchera du camp achéen, afin d'échapper à ses ennemis.

65. Sur ces aspects, voir Schmit-Neuerburg. 
66. Voir Hardie, p. 28-29 et 30 : soulignant les parallèles du chant 9 avec la course des deux Troyens lors des jeux du chant 5 , il indique entre autres leur incapacité à passer du monde de la jeunesse adonnée au sport au monde adulte du vrai combat.

67. Cf. exempli gratia Klingner, p. 563. F. Klingner: Virgil. Bucolica; Georgica; Aeneis, Zürich Stuttgart, 1967.

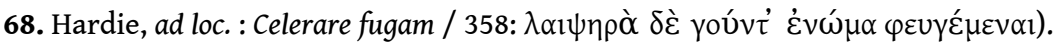

69. «Les ténèbres des branches et son pesant butin embarrassent Euryale » Ce motif de la fuite alourdie par le butin se trouve également dans l'Armorum Iudicium du chant 13 des Métamorphoses à propos d'Ulysse qu'Ajax imagine emportant avec difficulté les armes d'Achille et, selon Mario Labate, p. 30-31 « en se référant à un exemplum mémorable, Ovide accuse pour ainsi dire Ulysse (qui ne se souvient pas de l'Enéide) de mauvaise mémoire littéraire »: Et fuga, qua sola cunctos, timidissime, uincis, / tarda futura tibi est gestamina tanta trahenti?

70. Van der Valk, ad loc., p. 119 (apparat), considère que ce raisonnement est le propre d'Eustathe lui-même, vraisemblablement du fait que l'on n'en trouve pas trace dans les scolies, mais nous avons vu supra que cet argument a silentio n'est pas pleinement convaincant. Le fait qu'il s'agisse, chez Eustathe comme dans l'Enéide, d'une fuite entravée par le butin dans le contexte d'une Nyctegresia semble exclure la probabilité d'une coïncidence. Knauer ne renvoie d'ailleurs à aucun passage des poèmes homériques comme modèle éventuel pour les vers 383-384. En outre, les parallèles cités infra entre le texte d'Eustathe, celui de l'Enéide et celui de la Thébaïde de Stace semblent un peu trop précis pour relever de la simple coïncidence.

71. "Mais pourquoi, peu après, Diomède sautant à terre, remit entre les mains d'Ulysse les dépouilles $<$ de Dolon > qui sont une charge pour un homme à pied : mieux vaudrait qu'Ulysse, s'il est à pieds, s'en saisisse et les tende à Diomède, qui est à cheval, de sorte que celui qui chemine à pieds soit léger et sans fardeau ».

72. «Si seul Diomède était monté à cheval, conformément à la lettre du texte homérique, comment Ulysse aurait-il pu, à pied, courir jusqu'aux nefs à côté des chevaux qui, à ce que dit le poète, volaient ; à moins qu'il n'eût des talonnières ailées, comme le Persée représenté par les auteurs, "aux pieds de harpie" pour reprendre l'expression consacrée ».

73. «Le premier s'élance, bien avant tous les autres, Nisus, plus rapide que les vents et que les ailes de la foudre ».

74. «Jadis, Dymas précédait la course de chevaux aux jambes ailées, mais maintenant, il suivait, retardé par son âge ».

75. Une autre question consiste à déterminer si l'imitatio statienne opère une simple variation sur le modèle virgilien ou si elle se réfère directement à un commentaire homérique. Ce qu'il y a de frappant, c'est que Stace procure en outre une espèce de solution anticipée à la capture de Dymas qui adviendra dans le chant 10 : nunc aeuo tardante senectus.

76. Schlunk, p. 71 sqq.; Schmit-Neuerburg, p. 57 sq.

77. Voilà comment s'expliquent les particularités du casque de Diomède (10, 257-258): Scholie $\mathrm{A}$

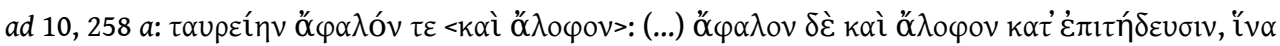

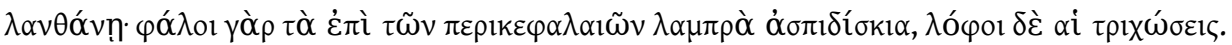

78. Hardie, ad loc.; Schmit-Neuerburg, p. 57-58.

79. Hopkinson, p. 102, ad Met. 13, 105-106.

80. Conon apud Photium, Biblioth., 137, a 8 (3, 25 Henry)= fr. 25 Bernabé. On peut se demander s'il n'y a pas lieu de rapprocher le fr. 9 Bernabé, qui mentionne le lever de la lune. Schlunk, p. 71, note qu'il n'y a pas de mention de la lune dans l'épisode de Nisus et Euryale.

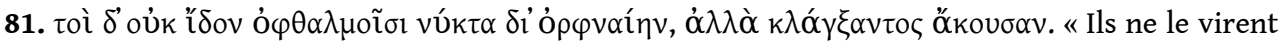
pas de leurs yeux, à travers la nuit obscure, mais ils entendirent son cri ».

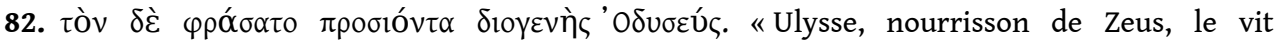
s'approcher » 
83. «'Un homme vient du côté de l'armée <troyenne>' : comment, alors qu'ils n'ont pas vu le héron, 'à travers la nuit ténébreuse $(10,276)$ ' voient-ils maintenant Dolon? peut-être la lune

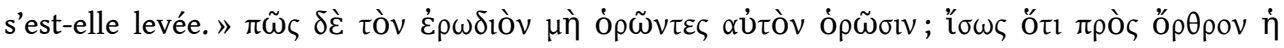

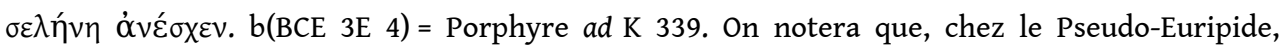
l'insistance est mise sur l'ouie, lorsqu'Ulysse et Diomède arrivent dans les parages du camp

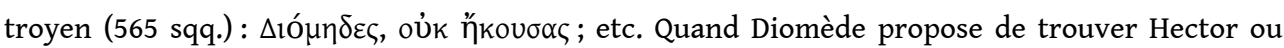

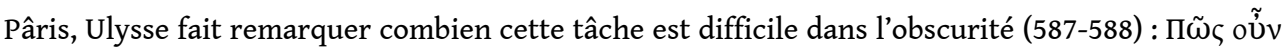

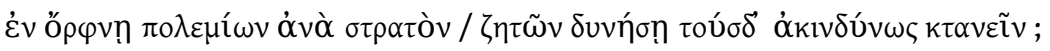

84. Servius commente ainsi : sublustri noctis in umbra: sublustris nox est habens aliquid lucis (...) radiis lunaribus intellegendum.

85. Ernout et Meillet, ad verbum: «Temere est proprement l'ablatif instrumental d'un substantif *temus, -eris « obscurité », cf. tenebrae. ».

86. Sur les jeux de mots étymologiques chez Virgile, voir O'Hara, True Names.

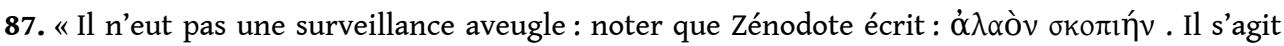
d'une expression proverbiale : il n'est pas aveugle pour ce qui est d'observer, mais au contraire il voit d'un œil perçant. ». Comparer la scholie D ad 515, qui ne retient que le sens métaphorique :

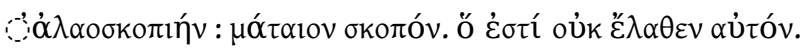

88. Ce n'est apparemment pas le cas de Servius qui commente: haud temere particula haec modo 'non sine causa' significat, alias 'fortuito', alias 'male', alias 'inprouide', alias 'passim', ut temere inter lora iacentes, alias 'facile': Plautus rapidus fluuius est hic, non hac temere transiri potest: quae pro loco accipiuntur et intelleguntur. aduerbium sane qualitatis relatum est.

89. 617-618.

90. Cette troisième "coïncidence" me semble garantir sans plus de doute possible que le commentaire d'Eustathe, au moins pour cette partie de la Dolonie, dépend de sources antiques qui ne nous sont pas parvenues.

91. «Il faut voir qu'en vérité l'apparition d'Apollon signifie ici l'arrivée du soleil, comme il apparaît selon la lettre même du texte, puisqu'elle réveille le cousin de Rhésos (sc. Hipocoon), qui n'a plus sommeil et détourne immanquablement les espions (sc. Ulysse et Diomède) vers les navires. "

92. Eustathe résout apparemment, en 821,27 , la question de l'intervention d'Apollon en faveur des Troyens par le fait que le poète, en dépit de son philhellénisme, ne peut priver les Troyens d'une aide divine et que de toute façon le rôle joué par Athéna, qui aide Diomède et Ulysse, est ici plus important. A la lumière de ces remarques, on notera que les dieux ont abandonné les héros de la Nyctegresia dans l'Enéide.

\section{AUTEUR}

\section{JEAN-CHRISTOPHE JOLIVET}

Université Charles-de-Gaulle - Lille 3 